\title{
Characteristics of Bacterial Communities in Biological Filters of Full-Scale Drinking Water Treatment Plants
}

\author{
Yonkyu Choi ${ }^{1,2 *}$, Yeongseop $\mathrm{Cha}^{1}$, and Bogsoon $\mathrm{Kim}^{1}$ \\ ${ }^{1}$ Seoul Water Institute, Seoul 04981, Republic of Korea \\ ${ }^{2}$ Department of Agricultural Biotechnology, Seoul National University, Seoul 08826, Republic of Korea
}

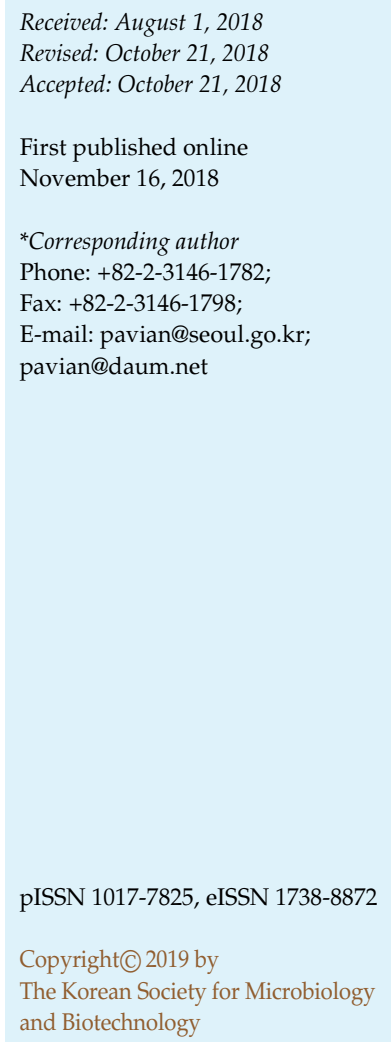

The taxonomic and functional characteristics of bacterial communities in the pre-chlorinated rapid filters and ozonated biological activated carbon (BAC) filters were compared using Illumina MiSeq sequencing of the 16S rRNA gene and community-level physiological profiling (CLPP) based on sole-carbon-source utilization patterns. Both the rapid filters and BAC filters were dominated by Rhizobiales within $\alpha$-proteobacteria, but other abundant orders and genera were significantly different in both types of filter. Firmicutes were abundant only in the intermediate chlorinated rapid filter, while Acidobacteria were abundant only in the BAC filters. Bacterial communities in the rapid filter showed high utilization of carbohydrates, while those in the BAC filters showed high utilization of polymers and carboxylic acids. These different characteristics of the bacterial communities could be related to the different substrates in the influents, filling materials, and residual disinfectants. Chlorination and ozonation inactivated the existing bacteria in the influent and formed different bacterial communities, which could be resistant to the oxidants and effectively utilize different substrates produced by the oxidant, including Phreatobacter in the rapid filters and Hyphomicrobium in the BAC filters. Bradyrhizobium and Leptothrix, which could utilize compounds adsorbed on the GAC, were abundant in the BAC filters. Ozonation increased taxonomic diversity but decreased functional diversity of the bacterial communities in the BAC filters. This study provides some new insights into the effects of oxidation processes and filling materials on the bacterial community structure in the biological filters of drinking water treatment plants.

Keywords: Bacterial community, substrate utilization, rapid filter, biological activated carbon filter, biological filter, drinking water

\section{Introduction}

Biological filtration refers to the process of removing both particulate matter and biodegradable organic matter (BOM) from water [1]. Biological filters can remove organic compounds through the fixed biofilm that develops on various media such as sand, anthracite, granular activated carbon (GAC), or membranes [2]. The biologically active rapid filter and the biological activated carbon (BAC) filter have been widely used for decades in drinking water treatment plants [1-3]. The rapid filter is usually filled with sand or anthracite, and is considered the most economical way to remove particles and BOM with the same filter unit
[1]. However, many previous studies have demonstrated that the BAC filter is a more appropriate process to remove $\mathrm{BOM}$ than the rapid filter $[4,5]$. Generally, the combination of ozonation and GAC filter is referred to as the BAC process [3]. Ozonation converts high-molecular-weight refractory organic matter into low-molecular-weight BOM, and this increased BOM can be effectively removed by the bacteria attached to the BAC filter [1, 4, 6-8].

Biological filtration has many advantages for drinking water treatments. First of all, it is important to increase the biostability of drinking water by reducing the quantity of BOM which can cause bacterial regrowth in distribution systems [1, 3-5]. It can reduce the disinfection by-product 
(DBPs) precursors and chlorine demand, which can help to maintain stable residual chlorine in the distribution system $[1,3]$. Biological filtration can also remove various biodegradable micropollutants including taste and odor compounds [1-3, 9]. Furthermore, an active biofilm can extend the lifetime of a GAC filter by bio-regeneration [3].

However, there is a lack of information about which microorganisms are involved in the functions [2]. It is necessary to identify the attached microorganisms and characterize the microbial communities of various biological filters in order to determine the role of microorganisms and enhance the removal of biodegradable contaminants. Especially, the change of microbial community in the biological filters after the oxidation process is important to produce biologically stable drinking water in full-scale water treatment plants. Bacteria have a unique substrate preference $[10,11]$, so the change of microbial composition in biological filters can result in removal of different BOM in water. Both chlorination and ozonation can increase the BOM concentration, but they can produce different kinds of substrates $[8,12,13]$. Without the dominance of bacteria utilizing new substrates produced by those oxidants, biological filters cannot effectively remove the increased BOM, which can cause bacterial regrowth in the distribution system $[14,15]$. In addition, understanding the microbial community in a biological filter is useful in terms of public health because the biofilm in a biological filter can be a source of microbial contamination in the distribution systems [16]. It is also possible to screen pathogenic or disinfection resistant microorganisms and adopt appropriate measures to control them in advance $[17,18]$.

Recently, many researchers have used molecular biological methods to evaluate microbial community structures in the aquatic ecosystem. In particular, next-generation sequencing (NGS) is a culture independent and high-throughput method of analyzing the structure of an entire microbial community [10, 19, 20]. In addition, community-level physiological profiling (CLPP) based on sole-carbon-source utilization (SCSU) patterns has deepened understanding of the metabolic ability and functional characteristics of microbial communities [21]. In this study, therefore, Illumina MiSeq sequencing of the 16S rRNA gene and CLPP were used to investigate the characteristics of bacterial communities attached to the biological filters in full-scale drinking water treatment plants.

The main purposes of this study were 1) to compare the differences in the taxonomic and functional characteristics of bacterial communities in rapid filters and BAC filters which received pre-chlorinated water and ozonated water, respectively; 2) to investigate the relationship between the taxonomic composition and substrate utilization patterns of bacterial communities; and 3) to elucidate how the different oxidation processes, i.e., chlorination vs ozonation, effect on the bacterial communities of biological filters.

\section{Materials and Methods}

\section{Study Sites and Sampling}

This study was conducted at three, full-scale water treatment plants (WTPs) in Seoul, South Korea (Fig. 1). All three WTPs use the surface water of the Han River as source water, and consist of conventional and advanced water treatment processes. The conventional treatment includes pre-chlorination, coagulationsedimentation, and rapid filtration; whereas the advanced treatment includes ozonation and BAC filtration, and postchlorination finally follows the advanced treatment. Prechlorination was applied at the intake of the raw water, and ozone was added after the rapid filters of the WTPs. Intermediate chlorine was added after sedimentation only at WTP2. The rapid filters of WTP1 and WTP3 are filled with sand, while WTP2 has a dual media (anthracite/sand) rapid filter. The BAC filters are filled with coal-based granular activated carbon (GAC), and the empty bed contact time (EBCT) is $15 \mathrm{~min}$. The detailed design and

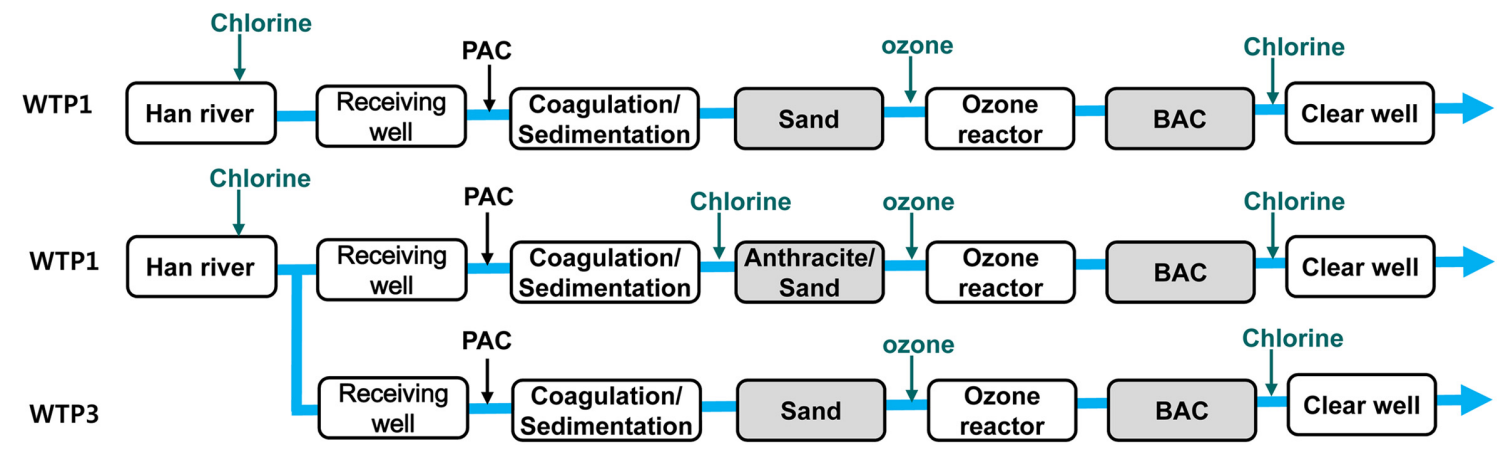

Fig. 1. Flow diagram of processes in the three drinking water treatment plants.

PAC (poly aluminium chloride): coagulant 
Table 1. Design and operational parameters of biological filters and water quality of influents in three WTPs.

\begin{tabular}{|c|c|c|c|}
\hline & WTP1 & WTP2 & WTP3 \\
\hline Capacity (m³/day) & $1,100,000$ & 450,000 & 720,000 \\
\hline \multicolumn{4}{|l|}{ Raw water quality } \\
\hline Temperature $\left({ }^{\circ} \mathrm{C}\right)$ & 18.7 & 20.9 & 20.4 \\
\hline TOC (mg/l) & 2.7 & 2.7 & 2.7 \\
\hline $\mathrm{pH}$ & 8.0 & 7.3 & 7.6 \\
\hline \multicolumn{4}{|l|}{ Disinfection dose (mg/l) } \\
\hline Pre-chlorine & 2.2 & 2.2 & 2.0 \\
\hline Intermediate chlorine & - & 0.6 & - \\
\hline Ozone & 0.4 & 0.5 & 0.6 \\
\hline \multicolumn{4}{|l|}{ Rapid filter } \\
\hline Media/depth (m) & Sand 1.2 & Anthracite 1.0/sand 0.3 & Sand 1.2 \\
\hline Effective diameter (mm) & 0.9 & $1.0 / 0.5$ & 0.9 \\
\hline \multicolumn{4}{|l|}{ Influent water } \\
\hline TOC (mg/l) & 1.0 & 1.4 & 1.3 \\
\hline $\mathrm{pH}$ & 7.1 & 7.1 & 7.3 \\
\hline Residual chlorine (mg/l) & 0.24 (monthly) & 0.50 (monthly) & 0.36 (monthly) \\
\hline Running time (year) & 29 & 0.5 & 17 \\
\hline \multicolumn{4}{|l|}{ BAC filter } \\
\hline Coal-based GAC (made in) & China & USA (Calgon carbon) & China \\
\hline Effective diameter (mm) & 0.68 & 0.63 & 0.86 \\
\hline Depth (m) & 2.5 & 2.5 & 2.9 \\
\hline $\mathrm{EBCT}(\mathrm{min})^{\mathrm{a}}$ & 15 & 15 & 15 \\
\hline \multicolumn{4}{|l|}{ Influent water } \\
\hline TOC (mg/l) & 1.1 & 1.2 & 1.2 \\
\hline $\mathrm{pH}$ & 7.1 & 7.1 & 7.0 \\
\hline Running time (year) & 1 & 0.5 & 1 \\
\hline
\end{tabular}

${ }^{a}$ EBCT (Empty bed contact time) = bed volume of filter media/flow rate

operational parameters of the three WTPs are shown in Table 1.

The conventional processes have been operated for decades, except for WTP2; whereas the advanced treatment of the three WTPs commenced in October 2014 (WTP2, April 2015). For the purposes of this study, after one year of operation, the filling materials (media) were taken from the rapid filters and BAC filters of the three WTPs in October 2015. The media were collected from the top layer at about $1 \sim 2 \mathrm{~cm}$ below the surface of all the biological filters using a core sampler. The collected medium samples were then placed in a sterilized bag and mixed well, after which the taxonomic composition and substrate utilization of the attached bacterial communities in the mixed medium samples were investigated. The residual chlorine in the water samples was measured using a Hach pocket chlorine colorimeter.

\section{Next-Generation Sequencing of Bacterial Communities}

The DNA of the attached bacteria was extracted from the media of the biological filters using a Fast DNA Spin Kit for soil (MP
Biomedicals), and the extracted DNA was amplified and sequenced by ChunLab Inc. (Korea).

Briefly, the extracted DNA was amplified by polymerase chain reaction (PCR) using the primers $341 \mathrm{~F}$ and $805 \mathrm{R}$, targeting the V3 to $\mathrm{V} 4$ regions of the $16 \mathrm{~S}$ rRNA gene. Then, secondary amplification was performed in order to attach the Illumina NexTera barcode using an i5 forward primer and an i7 reverse primer. The condition of the PCR and the sequences of primers are shown in Table 2. The PCR products were purified using a QIAquick PCR cleanup kit (Qiagen, USA). Equal concentrations of the purified products were pooled together, and non-target products were removed with an Ampure beads kit (Agencourt Bioscience, USA). The size and quality of the products were determined by a Bioanalyzer 2100 (Agilent, USA) with a DNA 7500 chip. Mixed amplicons were pooled and sequencing was carried out with a Miseq Sequencing system (Illumina, USA).

The EzTaxon database was used for taxonomic assignment [22, 23], and similarity was analyzed using pairwise alignment. The 
Table 2. Condition of PCR and sequences of primers.

\begin{tabular}{|c|c|c|}
\hline & Forward & Reverse \\
\hline $\begin{array}{l}\text { DNA } \\
\text { amplification }\end{array}$ & $\begin{array}{l}\text { 341F } \\
\text { (5'-TCGTCGGCAGCGTCAGATGTGTATA- } \\
\text { AGAGACAGCCTACGGGNGGCWGCAG-3' }\end{array}$ & $\begin{array}{l}\text { 805R } \\
\left(5^{\prime} \text {-GTCTCGTGGGCTCGGAGATGTGTAT- }\right. \\
\text { AAGAGACAGGACTACHVGGGTATCTAATCC-3') }\end{array}$ \\
\hline $\begin{array}{l}\text { secondary } \\
\text { amplification } \\
X \text { : barcode region }\end{array}$ & $\begin{array}{l}\text { i5 } \\
\left(5^{\prime} \text {-AATGATACGGCGACCACCGAGATC- }\right. \\
\text { TACAC-XXXXXXXX-TCGTCGGCAGCGTC-3') }\end{array}$ & $\begin{array}{l}\text { i7 } \\
\left(5^{\prime} \text {-CAAGCAGAAGACGGCATACGAGAT-XXXXXXXX- }\right. \\
\text { AGTCTCGTGGGCTCGG-3') }\end{array}$ \\
\hline $\begin{array}{l}\text { PCR } \\
\text { amplification } \\
\text { conditions }\end{array}$ & $\begin{array}{l}\text { initial denaturation at } 95^{\circ} \mathrm{C} \text { for } 3 \mathrm{~min} \\
25 \text { cycles: denaturation at } 95^{\circ} \mathrm{C} \text { for } 30 \mathrm{sec} \text { (secon } \\
\quad \text { primer annealing at } 55^{\circ} \mathrm{C} \text { for } 30 \mathrm{sec} \\
\quad \text { extension at } 72^{\circ} \mathrm{C} \text { for } 30 \mathrm{sec} \\
\text { final elongation at } 72^{\circ} \mathrm{C} \text { for } 5 \mathrm{~min}\end{array}$ & ification : 8 cycles) \\
\hline
\end{tabular}

sequences were clustered using CD-Hit7 and UCLUST8, and the operational taxonomic units (OTUs) were defined based on similarity (cutoff 97\%). The two richness parameters, i.e., Chao and abundance-based coverage estimators (ACE), and two diversity parameters, i.e., the Shannon index and the Simpson index, were calculated using the CLcommunity program based on the CD-Hit clustering method (ChunLab Inc., Korea). To compare the bacterial community diversity between the samples, principal coordinate analysis (PcoA) and permutational analysis of variance (PERMANOVA) tests were performed using BIOiPLUG bioinformatics cloud platform using Jensen-Shannon divergence (ChunLab Inc., Korea).

\section{Analysis of Community Level Physiological Profiling (CLPP)}

Biolog EcoPlates (Biolog, Inc., USA) were used to compare the characteristics of substrate utilization by the bacterial communities attached to the biological filters. EcoPlates consist of 96-well plates containing 31 different substrates and one blank in three replications (Table 3). $10 \mathrm{~g}$ of each medium sample was placed in $90 \mathrm{ml}$ of sterilized $\mathrm{NaCl}$ solution $(0.85 \%)$ with sodium thiosulfate in a 250-ml Erlenmeyer flask, which was shaken at $250 \mathrm{rpm}$ for $30 \mathrm{~min}$ to detach the bacteria. After settling large particles for $30 \mathrm{~min}, 50 \mathrm{ml}$ of supernatant was taken and filtered with a $5-\mu \mathrm{m}$ sterilized syringe filter to remove particulate matters. $150 \mu$ of the filtrate was inoculated into each well of the EcoPlates, which were then incubated at $25^{\circ} \mathrm{C}$ for 7 days. The absorbance of the EcoPlates was measured at $620 \mathrm{~nm}$ every day using a microplate reader (Ascent Multiscan, Labsystem).

The bacterial activity (Ai) of each substrate was calculated by subtracting the absorbance value of the blank from the absorbance value obtained for each substrate. The threshold of the Ai was set at 0.1 after considering the variation of blank absorbance, so any Ai values above 0.1 were considered to be positive. The average bacterial activity of the substrates in the EcoPlates was expressed as Average Well Color Development (AWCD), as shown in the following equation [24].

$$
\mathrm{AWCD}=\Sigma \mathrm{Ai} / 31=\Sigma(\mathrm{ODi}-\mathrm{C}) / 31
$$

where,

ODi: the mean absorbance value of the triplicate wells of each substrate.

C: the mean absorbance value of the triplicate blank wells.

$\mathrm{Ai}$ : the difference between the absorbance of each substrate and the blank absorbance

For functional diversity, Richness (R), the Shannon index $\left(\mathrm{H}^{\prime}\right)$ and the Simpson index (D) were calculated using an Ai above 0.1 on the fifth day, as expressed by the following equation [24, 25]:

Richness $(\mathrm{R})=$ number of substrates with $\mathrm{Ai}>0.1$

Shannon index $\left(\mathrm{H}^{\prime}\right)=-\Sigma$ pi $(\operatorname{lnpi})$

Simpson index $(\mathrm{D})=\Sigma(\mathrm{pi})^{2}$

$\mathrm{pi}=\mathrm{Ai} / \mathrm{n}, \mathrm{n}=-\Sigma \mathrm{Ai}$

where,

n: sum of Ai values of 31 substrates

pi: the ratio of the Ai value of each substrate to the sum of the Ai values of the 31 substrates

The 31 organic substrates in the EcoPlates were categorized into the following 6 groups according to Insam [26]: (1) amines, (2) amino acids, (3) carbohydrates, (4) carboxylic acids, (5) polymers, (6) phenolic compounds (Table 3).

\section{Results and Discussion}

The Taxonomic Composition of the Bacterial Communities

A comparison was made of the taxonomic composition of the bacterial communities in two rapid filters and three BAC filters. In the case of the rapid filter of WTP3, the concentration of the extracted DNA was too low to acquire sequencing data. The relative abundance of the bacterial 
Table 3. Substrate utilization after 5 days by attached bacteria in the rapid filters and BAC filters of three WTPs.

\begin{tabular}{|c|c|c|c|c|c|c|c|}
\hline \multirow{2}{*}{ Category } & \multirow{2}{*}{ Substrate } & \multicolumn{2}{|c|}{ WTP1 } & \multicolumn{2}{|l|}{ WTP2 } & \multicolumn{2}{|c|}{ WTP3 } \\
\hline & & Sand & BAC & Anthracite/Sand & BAC & Sand & BAC \\
\hline \multirow[t]{10}{*}{ Carbohydrates } & D-Cellobiose & ++++ & - & - & + & - & - \\
\hline & $\alpha$-D-Lactose & - & - & - & - & - & - \\
\hline & $\beta$-Methyl-D-glucoside & +++ & - & - & - & - & - \\
\hline & D-Xylose & - & - & - & + & - & - \\
\hline & i-Erythritol & - & - & - & - & - & - \\
\hline & D-Mannitol & ++++ & - & - & + & + & - \\
\hline & N-Acetyl-D-glucosamin & +++ & ++ & - & + & - & - \\
\hline & Glucose-1-phosphate & ++ & - & - & - & - & - \\
\hline & D,L- $\alpha$-Glycerol phosphate & + & + & - & - & - & - \\
\hline & D-Galactonic acid $\gamma$-lactone & +++ & - & - & - & + & - \\
\hline \multirow[t]{7}{*}{ Carboxylic acids } & Pyruvic acid methyl ester & ++ & ++ & - & + & + & +++ \\
\hline & D-Glucosaminic acid & + & - & - & - & + & - \\
\hline & D-Galacturonic acid & - & - & - & ++ & + & - \\
\hline & $\gamma$-Hydroxybutyric acid & - & - & - & - & - & - \\
\hline & Itaconic acid & - & - & - & - & - & - \\
\hline & $\alpha$-Ketobutyric acid & - & + & - & + & - & - \\
\hline & D-Malic acid & - & + & - & + & - & - \\
\hline \multirow[t]{6}{*}{ Amino acids } & L-Arginine & - & - & - & - & + & - \\
\hline & L-Asparagine & +++ & ++ & - & + & + & ++ \\
\hline & L-Phenylalanine & - & + & - & + & - & + \\
\hline & L-Serine & ++ & + & - & + & + & - \\
\hline & L-Threonine & + & + & - & + & - & - \\
\hline & Glycyl-L-glutamic acid & +++ & + & - & + & - & - \\
\hline \multirow[t]{2}{*}{ Amines/amides } & Phenylethyl-amine & - & - & - & - & - & - \\
\hline & Putrescine & - & - & - & - & + & - \\
\hline \multirow[t]{2}{*}{ Phenolic compounds } & 2-Hydroxy benzoic acid & - & - & - & - & - & - \\
\hline & 4-Hydroxy benzoic acid & - & - & - & - & + & - \\
\hline \multirow[t]{4}{*}{ Polymers } & Tween 40 & - & + & - & ++ & - & - \\
\hline & Tween 80 & + & + & - & + & - & - \\
\hline & Cyclodextrin & - & + & - & + & - & - \\
\hline & Glycogen & + & + & - & ++ & - & - \\
\hline
\end{tabular}

communities in the five biological filter samples was shown at the phylum, class and order levels (Fig. 2).

At the phylum level, both the rapid filters and the BAC filters shared two dominant bacterial populations: Proteobacteria (58 74\%) and Bacteroidetes (11 23\%). However, Acidobacteria $(2 \sim 15 \%)$ were abundant only in the BAC filters, while Firmicutes $(11 \%)$ were abundant only in the rapid filter of WTP2. Some previous studies also reported the dominance of Acidobacteria only in the biofilm of BAC filters for drinking water treatment $[17,27]$. But how
Acidobacteria are selected in the biofilm of BAC filters is not yet understood. Meanwhile, some previous studies pointed to a high relative abundance of Nitrospirae in the biological filters of drinking water treatment plants $[28,29]$. In this study, however, only a very low level of Nitrospirae, i.e., average $0.07 \%$ and STD $0.13 \%$, was detected in all of the biological filters. This finding could be attributed to the low concentration of ammonia in influent water due to oxidation by pre-chlorination.

In the subclass of Proteobacteria, $\alpha$-proteobacteria (35 71\%) 


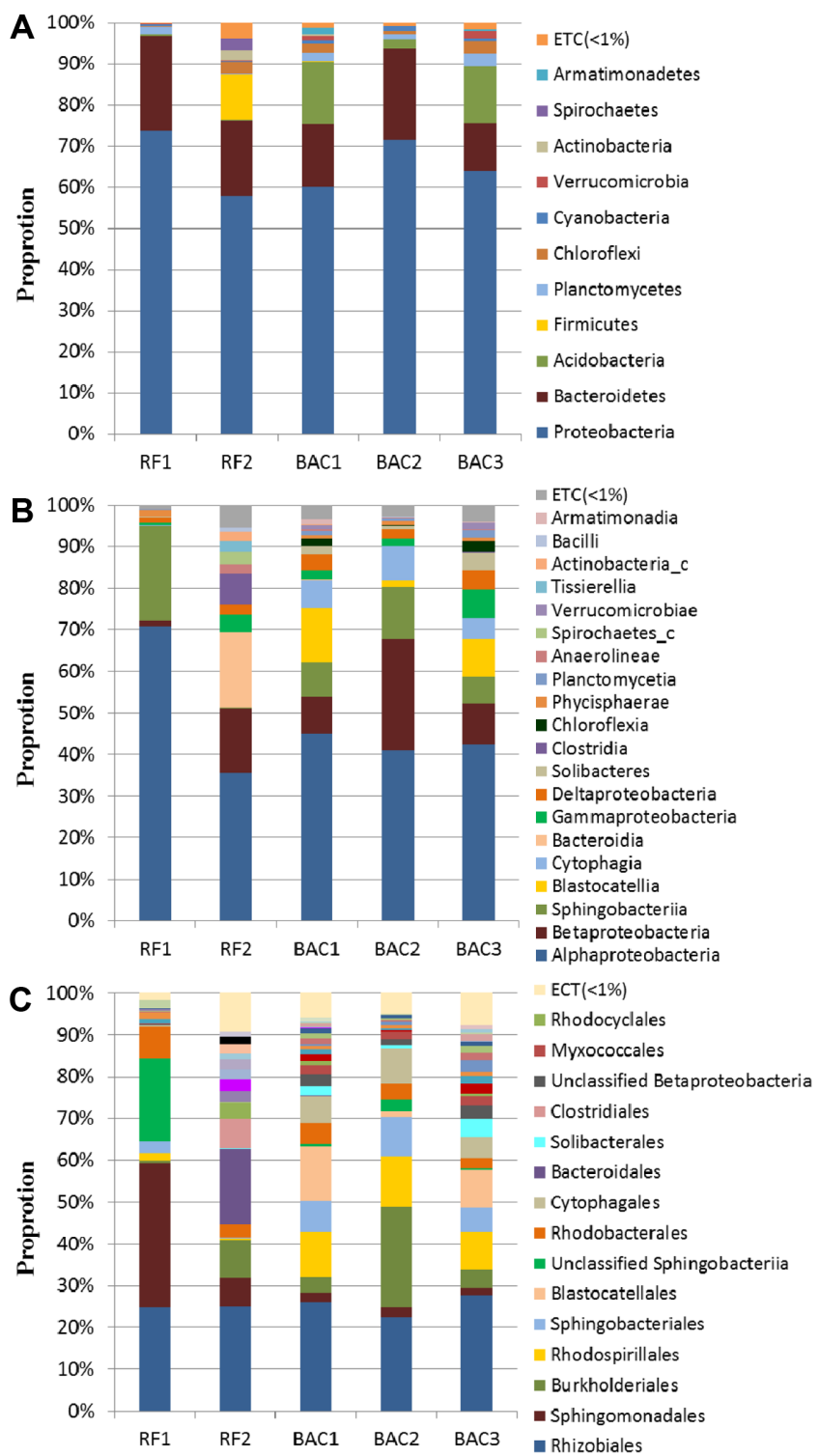

Fig. 2. Relative abundance of bacterial communities in the two rapid filters (RF) and three BAC filters at the phylum (A), class (B), and order level (C).

The remarks of the minor orders with a low relative abundance of $<3 \%$ are not shown.

were the most dominant class in all of the biological filters, followed by $\beta$-proteobacteria (1 27\%). $\gamma$-proteobacteria, a medically important group including many pathogens such as Salmonella, Yersinia, and Vibrio [30], showed low abundance $(0.4 \sim 7 \%)$ in both types of filter. Many previous studies have also reported the dominance of $\alpha$-proteobacteria in the biofilms of drinking water systems [18, 19, 28, 31, 32]. Generally, $\alpha$-proteobacteria and $\gamma$-proteobacteria are abundant in marine ecosystems, whereas $\beta$-proteobacteria and Actinobacteria are abundant in freshwater ecosystems [11]. This dominance of $\alpha$-proteobacteria in drinking water systems might be related to its competitiveness in the nutrient-poor conditions of drinking water treatment systems and their ability to degrade complex organic compounds, including humic substances [11]. Copiotrophic $\beta$ - and $\gamma$-proteobacteria can grow rapidly in nutrient-rich conditions, while oligotrophic $\alpha$-proteobacteria have low growth rates but can survive in chronic starvation conditions using low concentrations of substrates $[33,34]$. Therefore, $\alpha$-proteobacteria may have a disadvantage in nutrient-rich conditions such as wastewater, but they can outcompete $\beta$ - and $\gamma$-proteobacteria in nutrient-poor drinking water systems [11,33-36]. Besides $\alpha$ - and $\beta$-proteobacteria, the three BAC filters were dominated by Sphingobacteriia (6 13\%), Cytophagia (5 8\%) and Blastocatellia $(1 \sim 13 \%)$. The rapid filters of WTP1 and WTP2 were dominated by Sphingobacteriia (23\%) and Bacteroidia (18\%), respectively. Also, Clostridia (7\%), Tissierellia (2\%) and Bacilli (1\%) within Firmicutes were abundant only in the rapid filter of WTP2.

Both the rapid filters and the BAC filters showed a significant difference in bacterial composition below the order level although Rhizobiales within $\alpha$-proteobacteria were the commonly abundant order (22 28\%) in all of the biological filters. In particular, Rhodospirillales, Blastocatellales and Cytophagales were abundant orders in the BAC filters, while Sphingomonadales were abundant in the rapid filters. Previous studies have been reported that Rhizobiales were dominant in the biological filters of drinking water treatment plants, which may be related to their metabolic versatility and the ability to produce extracellular polymeric substances (EPS) that protects the bacteria from the harsh environment [18, 29, 37].

At the genus level, many dominant genera in the biological filters were related to uncultured bacteria, and minor genera with a low relative abundance of $<1 \%$ (ECT) accounted for the high percentage of bacterial communities. In the BAC filters, uncultured genus (FJ479296_g), Bradyrhizobium and Hyphomicrobium within Rhizobiales were dominant. In addition, Aridibacter, Lacibacter, Leptothrix, Reyranella and uncultured genera within Cytophagales (GU454944_g), $\beta$-proteobacteria (GQ263935_g) and Blastocatellales (EU335275_g) were more abundant in the BAC filters than the rapid filters. Conversely, Phreatobacter within Rhizobiales was dominant in the rapid filters, and Sphingomonas and Novosphingobium within Sphingomonadales were more abundant in the rapid filters compared to the BAC filters (Fig. 3). 


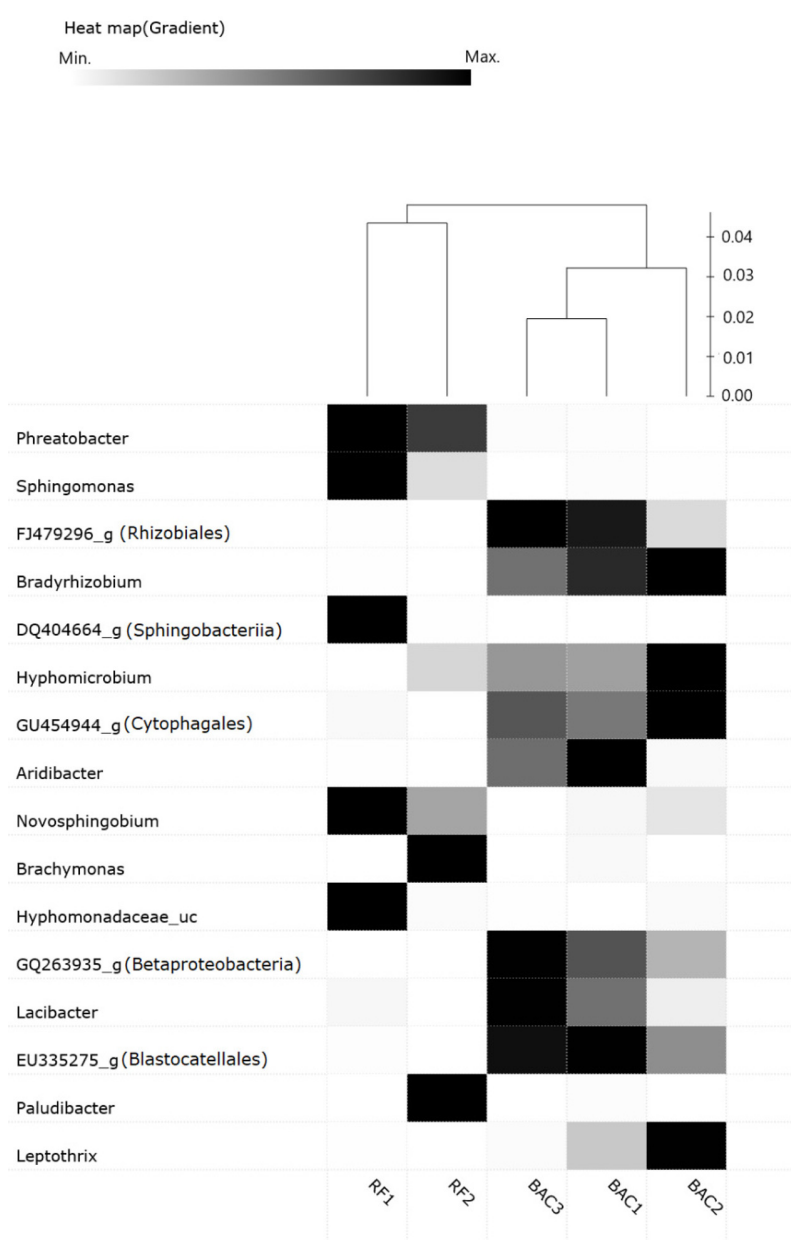

Fig. 3. Heat map showing the dominant genera of microbial communities in the rapid filters and BAC filters.

The minor genera with an average relative abundance of $<1 \%$ are not shown.

The composition of the bacterial communities in the rapid filters was significantly different from that of BAC filters at the $90 \%$ confidence level (PERMANOVA, $\mathrm{p}$ value = 0.09). The PcoA analysis showed that three BAC filters had a similar bacterial composition while the two rapid filters had a large variation in the bacterial composition (Fig. 4). Despite this large variation, the rapid filter samples were clearly separated from the BAC samples on the first principal coordinate. Also, in the heat map analysis, the common genera in the rapid filters were quite different from those of the BAC filters, so the two rapid filters (RF-1, 2 ) and the three BAC filters (BAC-1, 2, 3) were clustered, respectively (Fig. 3).

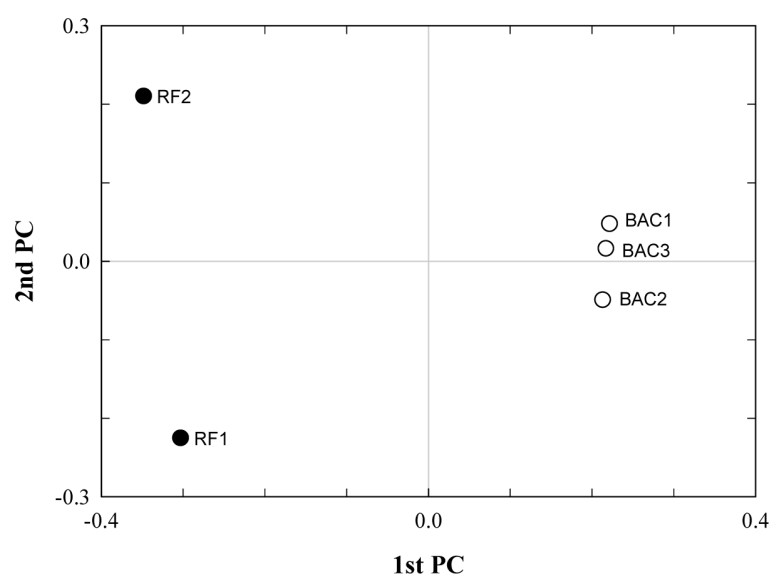

Fig. 4. Principal coordinate analysis (PcoA) of the five biological filter samples using Jensen-Shannon divergence from Illumina MiSeq sequencing.

\section{Characteristics of Substrate Utilization of Bacterial Community}

The AWCD as an indicator of average substrate utilization by the bacterial communities was compared between the rapid filters and the BAC filters of the three WTPs (Fig. 5). Except for WTP1, the AWCD of the rapid filters was low because the attached bacterial concentration of the rapid filters was low due to the residual chlorine in the influents. However, the level of AWCD was not proportional to the attached bacterial concentration in all of the biological filters. The rapid filter of WTP1 showed the highest AWCD, although the BAC filters of WTP1 and WTP2 had over 100 times more attached bacterial biomass than the rapid filter of WTP1 (data not shown). This implies that average substrate utilization is related not only to the bacterial concentration but also to the composition of the bacterial community. Although average substrate utilization can be a good indicator of bacterial metabolic ability, it cannot provide useful information on the functional characteristics of a bacterial community. Thus, the utilization levels of each substrate group in the rapid filter and the BAC filter of WTP1 were compared, wherein both filters showed a high level of average substrate utilization. The bacterial community of the rapid filter showed a high utilization of carbohydrates and amino acids, while that of the BAC filter showed a high utilization of polymers, amino acids and carboxylic acids (Fig. 6). In the BAC filters, especially, the contributions of carbohydrates to the utilization of six substrate groups drastically decreased, while the contribution of polymers and carboxylic acids increased (Fig. 7). A higher utilization of polymers, amino acids and carboxylic 


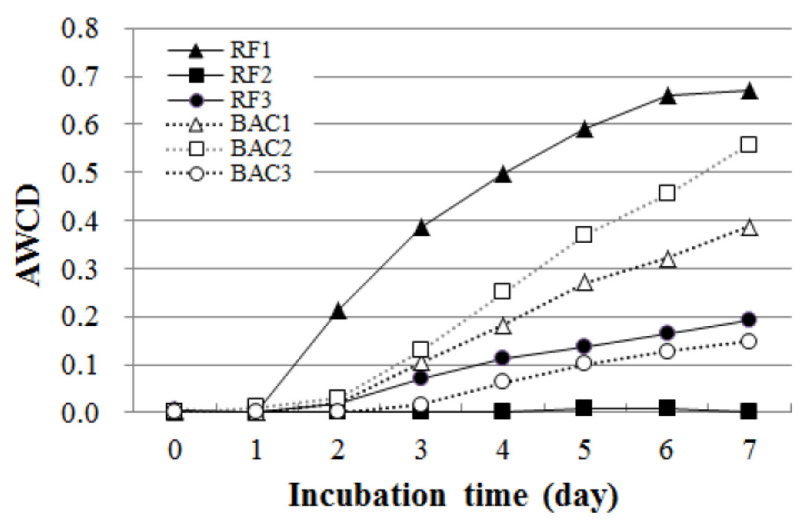

Fig. 5. Average substrate utilization by bacterial communities in the rapid filters and BAC filters of three WTPs.

acids was also observed in the BAC filter of WTP2 (Table 3).

\section{Taxonomic and Functional Diversity of Bacterial Communities}

The OTUs obtained by NGS sequencing ranged from 910 to 1,487 in the BAC filters, while those in the rapid filters ranged from 394 to 920 . The number of OTUs of the three BAC filters was higher than that of the two rapid filters, and the highest number of OTUs was observed in the BAC filter of WTP3 (Table 4). ACE and Chao, the parameters of richness, were higher in the bacterial communities of the BAC filters than in those of the rapid filters. The Shannon indices $\left(\mathrm{H}^{\prime}\right)$ of the bacterial communities in the BAC filters ranged from 4.72 to 5.09 , while those in the rapid filters ranged from 2.54 to 4.21; and the Simpson indices (D') of the bacterial communities in the BAC filters ranged from 0.017 to 0.028 , while those in the rapid filters ranged from 0.051 to 0.164 . These higher figures for ACE, Chao, the

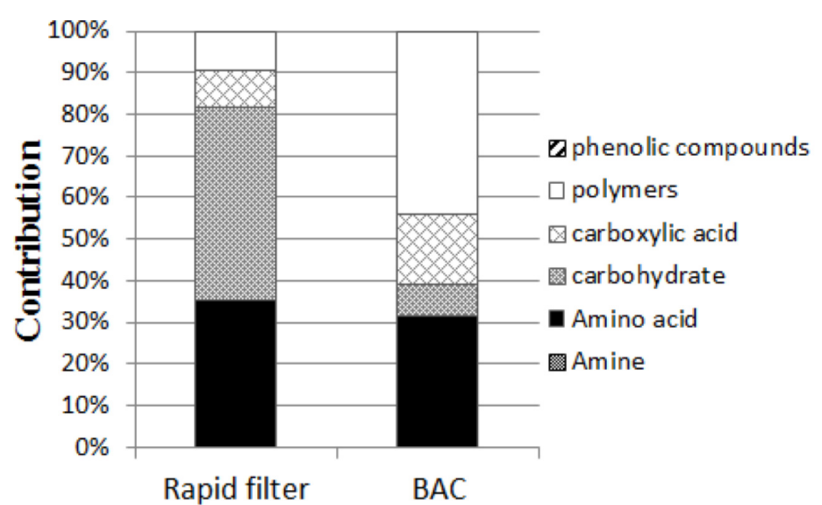

Fig. 7. The relative contribution of each substrate group to utilization of six substrate groups by bacterial communities in the rapid filter and BAC filter of WTP1.

Shannon index, and the lower Simpson index in the BAC filters indicated that BAC filters had a more diverse bacterial composition than the rapid filters [38].

On the other hand, the bacterial communities of the rapid filters showed higher functional diversity based on the substrate utilization patterns compared to those of the BAC filters. The substrate richness and the Shannon indices of the rapid filters were higher than those of the BAC filters, while the Simpson indices of the rapid filters were lower than those of the BAC filters (Table 5). The splitting of organic matter by ozonation could remove large organic compounds and produce a greater variety of small organic compounds $[6,7,39]$. This indicates that the total numbers of organic species could increase, but the kinds of available substrate groups could decrease, especially the highmolecular-weight organic fractions. Therefore, more varied bacteria using these various small organic matters could
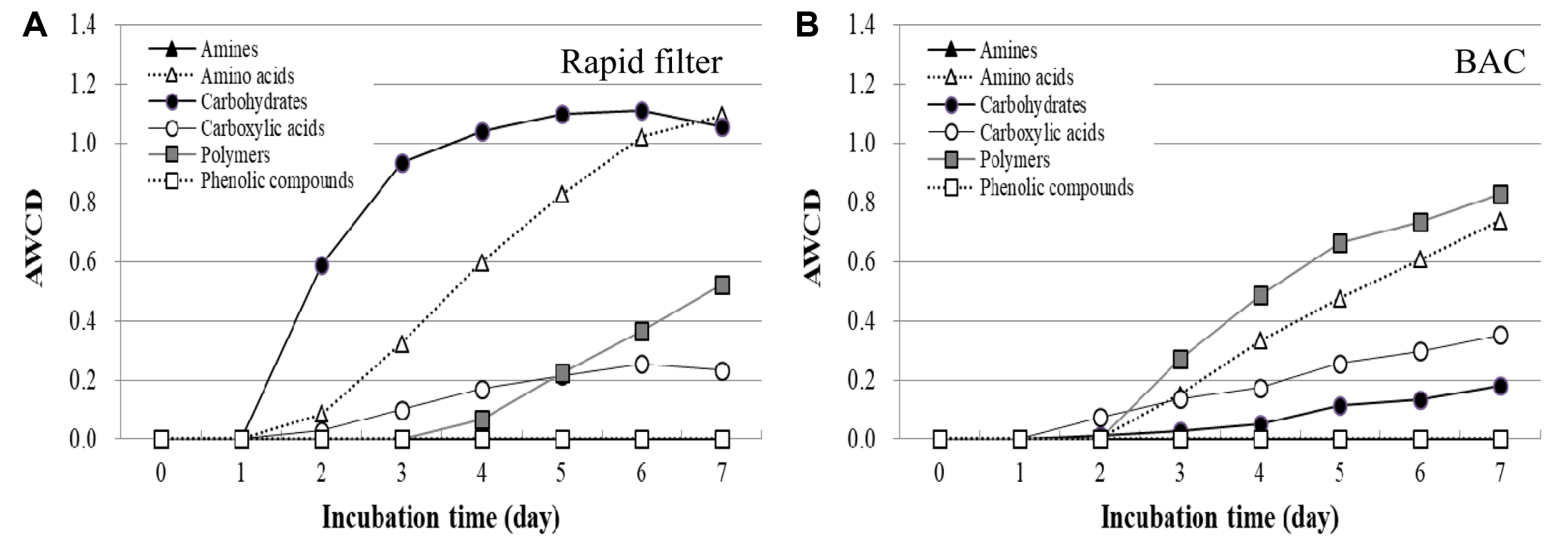

Fig. 6. Utilization of each substrate group by bacterial communities in the rapid filter (A) and BAC filter (B) of WTP1. 
Table 4. Taxonomic diversity statistics for bacterial composition in the rapid filters and BAC filters.

\begin{tabular}{cccccccc}
\hline & OUT & ACE & Chao & Coverage & Shannon & Simpson \\
\hline Rapid filter & 1 & 394 & 461 & 429 & 0.997 & 2.54 & 0.164 \\
& 2 & 920 & 1073 & 1032 & 0.994 & 4.21 & 0.051 \\
BAC filter & 3 & - & - & - & - & - & - \\
& 1 & 910 & 972 & 938 & 0.997 & 4.72 & 0.028 \\
& 2 & 1267 & 1305 & 1274 & 0.997 & 5.09 & 0.017 \\
\hline
\end{tabular}

grow in the BAC filters, but they could not utilize the relatively large organic matters, which resulted in an increase of the taxonomic diversity, but in a decrease of the functional diversity of substrate utilization in the BAC filters.

\section{Factors Influencing the Bacterial Community Structure of Biological Filters}

Different substrates in the influent water. The different substrates in the influent could cause differences in bacterial composition [10, 20, 40]. Pre-chlorinated water and ozonated water flowed into the three rapid filters and the three BAC filters, respectively. Both chlorine and ozone are good oxidants, but they can produce different kinds of substrates [6, 13]. Some previous studies showed changes of different fractions of DOM in the drinking water treatment process. Pre-chlorination increased the highmolecular-weight biopolymers and humic substances and low-molecular-weight neutrals, while ozonation increased the low-molecular-weight fractions including building blocks, neutrals, and organic acids [10, 41]. Biopolymers, neutrals, and organic acids are biodegradable, but their characteristics are different [42]. Biopolymers are highmolecular-weight organic matter of $>20 \mathrm{kDa}$ including polysaccharides and proteins. Neutrals are uncharged, small organic matter of <350 Da including alcohols, aldehydes, and ketones. Organic acids represent protic organic acids of low

Table 5. Functional diversity statistics based on the substrate utilization by bacterial communities in the rapid filters and BAC filters.

\begin{tabular}{ccccc}
\hline & & Richness & Shannon & Simpson \\
\hline Rapid filter & 1 & 15 & 2.5 & 0.09 \\
& 2 & - & - & - \\
& 3 & 10 & 2.2 & 0.11 \\
BAC filter & 1 & 14 & 2.4 & 0.10 \\
& 2 & 17 & 2.8 & 0.07 \\
& 3 & 3 & 1.0 & 0.44
\end{tabular}

molecular weight of $<350 \mathrm{Da}$ [43]. Pre-chlorination can increase high-molecular-weight substrates by disrupting particulate organic matter, including algae in raw water $[41,44]$. Algal organic matter (AOM) consists of biodegradable compounds including carbohydrates, proteins, lipids, amino acids and amine [44, 45]. Especially, the intracellular organic matter (IOM) of algae are relatively high-molecularweight compounds compared to extracellular organic matter (EOM) [44, 46]. Therefore, the disruption of algal cells by pre-chlorination can result in an increase of highmolecular-weight substrates by releasing IOM. Although those high-molecular-weight compounds can be removed by coagulation-sedimentation [41], the pre-chlorinated influent of the rapid filters might contain a higher concentration of relatively large substrates than the ozonated influent of the BAC filters.

Post-ozonation can break high-molecular-weight refractory dissolved organic matters and produce low-molecularweight oxygen-containing compounds, including aldehydes, ketones, carboxylic acids and keto acids, all of which are easily biodegradable $[1,6-8,39,47]$. On the other hand, chlorination can produce halogenated compounds, including trihalomethanes (THMs), haloacetic acids (HAAs), haloketones (HKs), and haloacetonitrils (HANs) [12,48]. These halogenated by-products are less biodegradable than ozonated by-products although some of them can be easily biodegraded [12]. Chlorination can also convert highmolecular-weight refractory organic matter such as aromatic, lignin, and phenolic compounds to biodegradable organic matter, including aliphatic, ester, alcoholic and carboxylic compounds [49]. However, ozone is a stronger oxidant than chlorine and produces more oxidized compounds with lower molecular weights than chlorine [6, $8,13]$. For instance, ozonation can convert carbohydrates, alcohols, and aldehydes into carboxylic acids, which have the highest oxidation state of organic compounds [8,50]. Świetlik et al. [13] reported that chlorine produced much fewer carboxylic acids than ozone. In this study, the utilization of carbohydrates decreased while that of 
carboxylic acids increased in the BAC filter. This could be attributed to the decrease of carbohydrates and the increase of carboxylic acids in the ozonated influent of the BAC filters. Moll et al. [51] also reported a significant decrease of carbohydrate utilization by bacterial communities in filters with the influent of ozonated water compared to filters with the influent of non-ozonated water. Xiang et al. [21] reported that carboxylic acids and polymers were utilized less than other substrate groups by the bacterial community in the BAC filter with the influent of nonozonated water.

In this study, Phreatobacter, the dominant genus in rapid filters, can use limited amounts of carbohydrates, alcohols and amino acids, but it cannot use carboxylic acids [52]. The other dominant bacteria in the rapid filters, i.e., Sphingomonas and Novosphingobium, can use various carbohydrates and degrade high-molecular-weight recalcitrant organic compounds, including chlorinated compounds and polycyclic aromatic hydrocarbons (PAH) [53-55]. Conversely, Hyphomicrobium, which was abundant in the BAC filters, can utilize low-molecular-weight $\mathrm{C} 1$ compounds including methanol, formaldehyde and formate [56]. GAC can adsorb the low-molecular-weight compounds produced by ozonation [47, 57]. Therefore, bacteria that utilize those low-molecular-weight compounds could be more likely to grow in the BAC filters than in the rapid filters. Kim et al. [58] reported the abundance of other methylotrophic bacteria including Methylobacter and Methylosoma which can utilize C1 compounds in BAC filter. Both Phreatobacter and Hyphomicrobium belong to the same order of Rhizobiales. Despite the similar proportion of Rhizobiales, the proliferation of completely different genera in the rapid filters and the BAC filters might be related to the substrate preference of the attached bacteria.

In the CLPP test, the utilization of polymers was higher in the BAC filters than in the rapid filters, which might be related to the abundance of the class Cytophagia only in the BAC filters. The family Cytophagaceae, i.e., major members of Cytophagia, can utilize various biopolymers including polysaccharides, proteins, and cellulose [59]. Kim et al. [31] also reported the abundance of Cytophagaceae (genus Ohtaekwangia) in the BAC filter.

\section{Filling Materials (Media)}

The filling materials could affect the bacterial communities of the biological filters. In this study, Bradyrhizobium was abundant only in the BAC filters, although it shows versatile substrate utilization, including various carbohydrates and alcohols [52]. This dominance of Bradyrhizobium in the BAC filters has also been reported in other studies [10, 27, 29]. A recent study reported that the metabolic pathway associated with aromatics degradation was significantly higher in the bacterial community of the BAC filter than that of the rapid sand filter, and Bradyrhizobium may play an important role in aromatics biodegradation [29]. This finding may be one of the explanations for the dominance of Bradyrhizobium only in the BAC filters since aromatic organic matter can be accumulated in the BAC filters by adsorption [57]. Inorganic compounds such as iron and manganese, which are minor components of GAC and can be adsorbed on GAC [60], can also affect bacterial composition. Bradyrhizobium is a nitrogen-fixing bacterium and iron is required for the synthesis of many components related to nitrogen fixation activity [61]. Therefore, nitrogen-fixing bacteria including Bradyrhizobium could effectively proliferate in the iron-containing BAC filters. Leptothrix, which was another abundant genus only in the BAC filters, is an important bacterium for the biological oxidation of iron and manganese [62]. Leptothrix could have a growth advantage in the BAC filters by oxidizing those adsorbed minerals. Oh et al. [29] reported that the iron metabolic pathway was significantly enriched in the bacterial community of the BAC filter over that of the rapid sand filter. This finding also supports the abundance of Leptothrix in the BAC filters.

In this study, attached bacterial biomass was much higher in the BAC filters than in the rapid filters. GAC can support a denser attached bacterial biomass than sand or anthracite since macroporous and the irregular structure of GAC can be more suitable for bacterial attachment due to protecting bacteria from adverse environment [1]. The surface charge of GAC can also enhance bacterial attachment, and the adsorption capacity of substrates and nutrients can promote the growth of attached bacteria in the GAC filters more so than in the rapid filters [3].

Attached bacteria can produce biopolymers such as polysaccharide and proteins, and develop biofilm that is an assemblage of those EPS and microbial cells $[48,63]$. Especially, Bradyrhizobium, which was abundant in the BAC filters, is known to produce significant quantities of EPS [64]. Therefore, the higher biomass of attached bacteria in the BAC filters could be another source of biopolymers due to the detached biofilm and the excretion of metabolites by the bacteria [27, 39, 48]. The increased biopolymers could result in the growth of polymer-utilizing bacteria in the BAC filter.

The high bacterial biomass and the dominance of EPSproducing bacteria in the BAC filters can adversely affect 
biofilter performance and water quality. The EPS released by attached bacteria can cause buildup of head loss of the filters and increase of DBP formation [27]. In addition, the detachment of accumulated bacteria can increase the bacterial concentration in the effluent $[65,66]$. Although these microbes can be easily disinfected by post-chlorination, some bacteria attached to GAC particles can be resistant to disinfectants [65,67]. To ensure the safety of effluent quality from those challenges, more enhanced operational measures may be required, including increasing disinfectant dose, backwashing frequency and intensity optimization, and the installation of membrane or sand filters after BAC filters [67].

The two rapid filters of WTP1 and WTP2 showed significant differences in their bacterial composition despite having the same chlorinated influents. This could be related to the different materials of media (sand for WTP1 and anthracite for WTP2). According to a study by Gerrity et al. [27], the bacterial communities of the anthracite filter and the BAC filter differed significantly, although the same ozonated water flowed into both filters. Although the cause is not clearly understood, these results imply that the physical and chemical characteristics of the filling materials might be one of the important factors that influence the bacterial composition in the biological filters.

\section{Disinfection}

The difference in the bacterial composition between the rapid filters and the BAC filters could be related to disinfection resistance. The phylum Firmicutes were abundant only in the rapid filter of WTP2. In the case of WTP2, the average residual chlorine in the influent of the rapid filter was highest due to intermediate chlorination, so chlorine resistant bacteria could have a growth advantage in the rapid filter of WTP2. Firmicutes have a gram-positive cell wall structure and can form endospores, making them resistant to disinfectants $[2,68]$. Previous research also showed a dramatic change in the bacterial community structure after chlorination, including the dominance of gram-positive bacteria $[17,69,70]$. Sphingomonadaceae, which have been detected in drinking water distribution systems due to their resistance to chlorine, were also abundant in both rapid filters $[17,71]$.

Actually, the bacterial composition of the biological filters is very complex and can be affected by various factors including temperature, $\mathrm{pH}$, dissolved oxygen, nutrients, and the age of the biofilms [16, 20, 31, 38, 72]. Although this study is not sufficiently broad in scope to fundamentally understand the bacterial community changes in the biological filters, it can provide some insights into the effects of the substrate changes caused by oxidation processes on the bacterial community structures in the biological filters of drinking water treatment plants.

The main conclusions of this study are as follows: (1) The bacterial communities in the rapid filters and BAC filters showed significant differences in their taxonomic composition and substrate utilization due to the different substrates in the influents, filling materials and residual disinfectants. (2) Both the rapid filters and BAC filters were dominated by Rhizobiales within $\alpha$-proteobacteria, but other abundant orders and genera were significantly different in both types of filter. Acidobacteria were abundant only in the BAC filters, while Firmicutes were abundant only in the intermediate chlorinated rapid filter. (3) Chlorination and ozonation could affect the characteristics of a bacterial community by inactivating the existing bacteria in the influent and producing different substrates. More various bacteria that utilize biopolymers and small ozone by-products were abundant in the BAC filters, while chlorine resistant and/ or less oxidized substrate-utilizing bacteria were abundant in the rapid filters. (4) Ozonation increased taxonomic diversity, but decreased functional diversity of the bacterial communities of the BAC filters.

\section{Acknowledgment}

This study was conducted as a part of a survey project of the Seoul Water Institute of Seoul Metropolitan government. We would like to thank the researchers of three WTPs for their help with sampling and operating the processes.

\section{Conflict of Interest}

The authors have no financial conflicts of interest to declare.

\section{References}

1. Urfer D, Huck PM, Booth SDJ, Coffey BM. 1997. Biological filtration for BOM and particle removal: a critical review. J. Am. Water Works Assoc. 89: 83-98.

2. Zhu IX, Getting T, Bruce D. 2010. Review of biologically active filters in drinking water applications. J. Am. Water Works Assoc. 102: 67-77.

3. Dussert BW, Van Stone GR. 1994. The biological activated carbon process for water purification. Water Eng. Manage. 141: $22-24$

4. Chien CC, Kao CM, Chen CW, Dong CD, Wu CY. 2008. Application of biofiltration system on AOC removal: column 
and field studies. Chemosphere 71: 1786-1793.

5. Liu W, Wu H, Wang Z, Ong SL, Hu JY, Ng WJ. 2002. Investigation of assimilable organic carbon (AOC) and bacterial regrowth in drinking water distribution system. Water Res. 36: 891-898.

6. Ramseier MK, Peter A, Traber J, von Gunten U. 2011. Formation of assimilable organic carbon during oxidation of natural waters with ozone, chlorine dioxide, chlorine, permanganate, and ferrate. Water Res. 45: 2002-2010.

7. Zhao X, Hu HY, Yu T, Su C, Jiang H, Liu S. 2014. Effect of different molecular weight organic components on the increase of microbial growth potential of secondary effluent by ozonation. J. Environ. Sci. 26: 2190-2197.

8. Siddiqui MS, Amy GL, Murphy BD. 1997. Ozone enhanced removal of natural organic matter from drinking water sources. Water Res. 31: 3098-3106.

9. Pham ND, Lee EH, Chae SH, Cho Y, Shin H, Son A. 2016. Bacterial community structure shifted by geosmin in granular activated carbon system of water treatment plants. J. Microbiol. Biotechnol. 26: 99-109.

10. Lautenschlager K, Hwang C, Ling F, Liu WT, Boon N, Köster $\mathrm{O}$, et al. 2014. Abundance and composition of indigenous bacterial communities in a multi-step biofiltrationbased drinking water treatment plant. Water Res. 62: 40-52.

11. Newton RJ, Jones SE, Eiler A, McMahon KD, Bertilsson S. 2011. A guide to the natural history of freshwater lake bacteria. Microbiol. Mol. Biol. Rev. 75: 14-49.

12. Tung HH, Xie YF. 2009. Association between haloacetic acid degradation and heterotrophic bacteria in water distribution systems. Water Res. 43: 971-978.

13. Świetlik J, Raczyk-Stanisławiak U, Nawrocki J. 2009. The influence of disinfection on aquatic biodegradable organic carbon formation. Water Res. 43: 463-473.

14. van der Kooij D, Hijnen WAM, Kruithof JC. 1989. The effects of ozonation, biological filtration and distribution on the concentration of easily assimilable organic carbon (AOC) in drinking water. Ozone Sci. Eng. 11: 297-311.

15. Lechevallier MW, Becker WC, Schorr P, Lee RG. 1992. AOC reduction by biological active filtration. Revue des sciences de l'eau. 5: 113-142.

16. Niemi RM, Heiskanen I, Heine R, Rapala J. 2009. Previously uncultured $\beta$-Proteobacteria dominate in biologically active granular activated carbon (BAC) filters. Water Res. 43: 50755086.

17. Li C, Ling F, Zhang M, Liu WT, Li Y, Liu W. 2017. Characterization of bacterial community dynamics in a fullscale drinking water treatment plant. J. Environ. Sci. 51: 21-30.

18. Lin W, Yu Z, Zhang H, Thompson IP. 2014. Diversity and dynamics of microbial communities at each step of treatment plant for potable water generation. Water Res. 52: 218-230.

19. Chao Y, Mao Y, Wang Z, Zhang T. 2015. Diversity and functions of bacterial community in drinking water biofilms revealed by high-throughput sequencing. Sci. Rep. 5: 10044-
10057.

20. Fykse EM, Aarskaug T, Madslien EH, Dybwad M. 2016. Microbial community structure in a full-scale anaerobic treatment plant during start-up and first year of operation revealed by high-throughput $16 \mathrm{~S}$ rRNA gene amplicon sequencing. Bioresour. Technol. 222: 380-387.

21. Xiang H, Lu X, Yin L, Yang F, Zhu G, Liu W. 2013. Microbial community characterization, activity analysis and purifying efficiency in a biofilter process. J. Environ. Sci. 25: 677-687.

22. Yoon SH, Ha SM, Kwon S, Lim J, Kim Y, Seo H, Chun J. 2017. Introducing EzBioCloud: a taxonomically united database of 16S rRNA gene sequences and whole-genome assemblies. Int. J. Syst. Evol. Microbiol. 67: 1613-1617.

23. Chun J, Lee JH, Jung Y, Kim M, Kim S, Kim BK, et al. 2007 EzTaxon: a web-based tool for the identification of prokaryotes based on $16 \mathrm{~S}$ ribosomal RNA gene sequences. Int. J. Syst. Evol. Microbiol. 57: 2259-2261.

24. Zhu L, Xiao Q, Shen Y, Li S. 2017. Microbial functional diversity responses to 2 years since biochar application in silt-loam soils on the Loess Plateau. Ecotoxicol. Environ. Saf. 144: 578-584.

25. Garland JL, Mills AL. 1991. Classification and characterisation of heterotrophic microbial communities on the basis of pattern of community-level sole-carbon-source utilization. Appl. Environ. Microbiol. 57: 2351-2359.

26. Insam H. 1997. A new set of substrates proposed for community characterization in environmental samples, pp. 259-260. In Insam H, Rangger A (eds.), Microbial CommunitiesFunctional versus structural approaches. Springer-Verlag, Berlin.

27. Gerrity D, Arnold M, Dickenson E, Moser D, Sackett JD, Wert EC. 2018. Microbial community characterization of ozone-biofiltration systems in drinking water and potable reuse applications. Water Res. 135: 207-219.

28. Feng S, Chen C, Wang QF, Zhang XJ, Yang ZY, Xie SG. 2013. Characterization of microbial communities in a granular activated carbon-sand dual media filter for drinking water treatment. Int. J. Environ. Sci. Technol. 10: 917-922.

29. Oh S, Hammes F, Liu WT. 2018. Metagenomic characterization of biofilter microbial communities in a full-scale drinking water treatment plant. Water Res. 128: 278-285.

30. Williams KP, Gillespie JJ, Sobral BWS, Nordberg EK, Snyder EE, Shallom JM, et al. 2010. Phylogeny of gammaproteobacteria. J. Bacteriol. 192: 2305-2314.

31. Kim TG, Yun J, Hong SH, Cho KS. 2014. Effects of water temperature and backwashing on bacterial population and community in a biological activated carbon process at a water treatment plant. Appl. Microbiol. Biotechnol. 98: 14171427.

32. Liao X, Chen $\mathrm{C}$, Wang $\mathrm{Z}$, Wan $\mathrm{R}$, Chang $\mathrm{CH}$, Zhang $\mathrm{X}$, et al. 2013. Changes of biomass and bacterial communities in biological activated carbon filters for drinking water treatment. Process Biochem. 48: 312-316. 
33. Koch AL. 2001. Oligotrophs versus copiotrophs. BioEssays 23: 657-661.

34. Eilers KG, Lauber CL, Knight R, Fierer N. 2010. Shifts in bacterial community structure associated with inputs of low molecular weight carbon compounds to soil. Soil Biol. Biochem. 42: 896-903.

35. Kurm V, van der Putten WH, de Boer W, Naus-Wiezer S, Gera Hol WH. 2017. Low abundant soil bacteria can be metabolically versatile and fast growing. Ecology 98: 555-564.

36. Kwon S, Kim TS, Yu GH, Jung JH, Park HD. 2010. Bacterial community composition and diversity of a full-scale integrated fixed-film activated sludge system as investigated by pyrosequencing. J. Microbiol. Biotechnol. 20: 1717-1723.

37. Pang CM, Liu WT. 2007. Community structure analysis of reverse osmosis membrane biofilms and the significance of Rhizobiales bacteria in biofouling. Environ. Sci. Technol. 41: 4728-4734.

38. Luo J, Liang H, Yan L, Ma J, Yang Y, Li G. 2013. Microbial community structures in a closed raw water distribution system biofilm as revealed by 454-pyrosequencing analysis and the effect of microbial biofilm communities on raw water quality. Bioresour. Technol. 148: 189-195.

39. Wu Y, Zhu G, Lu X. 2013. Characteristics of DOM and removal of DBPs precursors across O3-BAC integrated treatment for the micro-polluted raw water of the huangpu river. Water(Switzerland) 5: 1472-1486.

40. Yang BM, Liu JK, Chien CC, Surampalli RY, Kao CM. 2011. Variations in AOC and microbial diversity in an advanced water treatment plant. J. Hydrol. 409: 225-235.

41. Park JW, Kim HC, Meyer AS, Kim S, Maeng SK. 2016. Influences of NOM composition and bacteriological characteristics on biological stability in a full-scale drinking water treatment plant. Chemosphere 160: 189-198.

42. Huber SA, Balz A, Abert M, Pronk W. 2011. Characterisation of aquatic humic and non-humic matter with size-exclusion chromatography - organic carbon detection - organic nitrogen detection (LC-OCD-OND). Water Res. 45: 879-885.

43. Rutlidge H, Andersen MS, Baker A, Chinu KJ, Cuthbert MO, Jex $C N$, et al. 2015. Organic characterisation of cave drip water by LC-OCD and fluorescence analysis. Geochimica et Cosmochimica Acta 166: 15-28.

44. Fang J, Yang X, Ma J, Shang C, Zhao Q. 2010. Characterization of algal organic matter and formation of DBPs from chlor(am)ination. Water Res. 44: 5897-5906.

45. Wang H, Liu D, Lu L, Zhao Z, Xu Y, Cui F. 2012. Degradation of algal organic matter using microbial fuel cells and its association with trihalomethane precursor removal. Bioresour. Technol. 116: 80-85.

46. Li L, Gao N, Deng Y, Yao J, Zhang K. 2012. Characterization of intracellular \& extracellular algae organic matters (AOM) of Microcystic aeruginosa and formation of AOM-associated disinfection byproducts and odor \& taste compounds. Water Res. 46: 1233-1240.
47. Aeppli J, Dyer-Smith P. 1996. Ozonation and granular activated carbon filtration: the solution to many problems. In Proceedings of the First Australian Conference of the International Ozone Association; 1996 Feb; Sydney.

48. Ma D, Meng Y, Xia C, Gao B, Wang Y. 2015. Fractionation, characterization and $\mathrm{C}-, \mathrm{N}$-disinfection byproduct formation of soluble microbial products in MBR processes. Bioresour. Technol. 198: 380-387.

49. Wang H, Zhu Y, Hu C, Hu X. 2015. Treatment of NOM fractions of reservoir sediments: effect of UV and chlorination on formation of DBPs. Sep. Purif. Technol. 154: 228-235.

50. Sandhu HPS, Manthey FA, Simsek S. 2012. Ozone gas affects physical and chemical properties of wheat (Triticum aestivum L.) starch. Carbohydrate Polymers. 87: 1261-1268.

51. Moll DM, Summers RS, Breen A. 1998. Microbial characterization of biological filtration used for drinking water treatment. Appl. Environ. Microbiol. 64: 2755-2759.

52. Tóth EM, Vengring A, Homonnay ZG, Kéki Z, Spröer C, Borsodi AK, et al. 2014. Phreatobacter oligotrophus gen. nov., sp. nov., an alphaproteobacterium isolated from ultrapure water of the water purification system of a power plant. Int. J. Syst. Evol. Microbiol. 64: 839-845.

53. Castro-Gutiérrez VM, Rodríguez-Rodríguez CE, VargasAzofeifa I. 2012. Hydrocarbon degrading microflora in a tropical fuel-contaminated aquifer: Assessing the feasibility of PAH bioremediation. Int. J. Environ. Res. 6: 345-352.

54. Nohynek LJ, Suhonen EL, Nurmiaho-Lassila, EL, Hantula J, Salkinoja-Salonen M. 1995. Description of four pentachlorophenoldegrading bacterial strains as Sphingomonas chlorophenolica sp. nov. Syst. Appl. Microbiol. 18: 527-538.

55. Saxena A, Anand S, Dua A, Sangwan N, Khan F, Lal R. 2013. Novosphingobium lindaniclasticum sp. nov., a hexachlorocyclohexane $(\mathrm{HCH})$-degrading bacterium isolated from an HCH dumpsite. Int. J. Syst. Evol. Microbiol. 63: 21602167.

56. Harder W, Attwood MM. 1975. Oxidation of organic C1 compounds by Hyphomicrobium spp. Antonie van Leeuwenhoek 41: 421-429.

57. Schreiber B, Brinkmann T, Schmalz V, Worch E. 2005. Adsorption of dissolved organic matter onto activated carbon - the influence of temperature, absorption wavelength, and molecular size. Water Res. 39: 3449-3456.

58. Kim TG, Moon KE, Cho KS. 2013. The presence of significant methylotrophic population in biological activated carbon of a full-scale drinking water plant. J. Microbiol. Biotechnol. 23: 1774-1778.

59. Mcbride MJ, Liu W, Lu X, Zhu Y, Zhang W. 2014. The Family Cytophagaceae, pp. 577-593. In Rosenberg E, DeLong EF, Lory S, Stackebrandt E, Thompson F (eds.), The Prokaryotes-Other Major Lineages of Bacteria and The Archaea, 4th Ed. Springer-Verlag, Berlin.

60. Goher ME, Hassan AM, Abdel-Moniem IA, Fahmy AH, Abdo MH, El-sayed SM. 2015. Removal of aluminum, iron 
and manganese ions from industrial wastes using granular activated carbon and Amberlite IR-120H. Egypt. J. Aquat. Res. 41: 155-164.

61. Lesueur D, Diem HG, Meyer JM. 1993. Iron requirement and siderophore production in Bradyrhizobium strains isolated from Acacia mangium. J. Appl. Bacteriol. 74: 675-682.

62. van Veen WL, Mulder EG, Deinema MH. 1978. The Sphaerotilus-Leptothrix group of bacteria. Microbiol. Rev. 42: 329-356.

63. Donlan RM. 2002. Biofilms: microbial life on surfaces. Emerg. Infect. Dis. 8: 881-890.

64. Skorupska A, Janczarek M, Marczak M, Mazur A, Król J. 2006. Rhizobial exopolysaccharides: genetic control and symbiotic functions. Microb. Cell Fact. 5: 7.

65. Stewart MH, Wolfe RL, Means EG. 1990. Assessment of the bacteriological activity associated with granular activated carbon treatment of drinking water. Appl. Environ. Microbiol. 56: 3822-3829.

66. Chen Z, Yu T, Ngo HH, Lu Y, Li G, Wu Q, et al. 2018. Assimilable organic carbon (AOC) variation in reclaimed water: Insight on biological stability evaluation and control for sustainable water reuse. Bioresour. Technol. 254: 290-299.
67. Korotta-Gamage SM, Sathasivan A. 2017. A review: Potential and challenges of biologically activated carbon to remove natural organic matter in drinking water purification process. Chemosphere 167: 120-138.

68. de Hoon MJ, Eichenberger P, Vitkup D. 2010. Hierarchical evolution of the bacterial sporulation network. Curr. Biol. 20: R735-R745.

69. Mi Z, Dai Y, Xie S, Chen C, Zhang X. 2015. Impact of disinfection on drinking water biofilm bacterial community. J. Environ. Sci. 37: 200-205.

70. Norton CD, LeChevallier MW. 2000. A pilot study of bacteriological population changes through potable water treatment and distribution. Appl. Environ. Microbiol. 66: 268276.

71. Furuhata K, Kato Y, Goto K, Saitou K, Sugiyama JI, Hara M, et al. 2007. Identification of yellow-pigmented bacteria isolated from hospital tap water in Japan and their chlorine resistance. Biocontrol. Sci. 12: 39-46.

72. Mathieu L, Bouteleux C, Fass S, Angel E, Block JC. 2009. Reversible shift in the $\alpha-, \beta$ - and $\gamma$-proteobacteria populations of drinking water biofilms during discontinuous chlorination. Water Res. 43: 3375-3386. 